James, L. V., Rubbo, S. D. \& Gardner, J. F. (1956). J. gen. Microbiol. 14, 223-227

\title{
Isolation of High Acid-yielding Mutants of Aspergillus niger by a Paper Culture Selection Technique
}

\author{
By L. VALERIE JAMES, S. D. RUBBO AND JOAN F. GARDNER \\ School of Bacteriology, University of Melbourne, Australia
}

SUMMARY: A method for isolating and identifying high acid-yielding mutants of Aspergillus niger is described. This involves cultivation of the organisms on absorbent paper soaked in an indicator medium. The advantages of the technique and the criteria used for selecting biochemically interesting mutants are briefly described. The greater acid production of mutants selected by paper culture has been confirmed by comparing yields of citric acid in surface and submerged fermentations with those given by the wild type strain.

The selection of acid-producing fungi described by Foster \& Davis (1949) and modified by Quilico, Panizzi \& Visconti (1949) has been used frequently for isolating fungi showing marked differences in acid production. Their methods of cultivation on indicator media are unsatisfactory for selection of colonies which produce large amounts of acid because of the extensive diffusion of the acid zones around the colonies. With such strains large quantities of media are required since each colony to be screened would have to be tested on a separate agar plate, and there is no simple means of determining whether such colonies arise from one or more spores.

\section{METHODS}

The irradiation techniques used, and a description of the mutant strains isolated by the technique to be described, are given in the following paper (Gardner, James \& Rubbo, 1956).

\section{Paper culture selection technique}

The method depends on the ability of Aspergillus niger to grow as compact discrete colonies surrounded by clearly defined acid zones on absorbent paper previously soaked in liquid culture medium. There are a number of ways of carrying out this paper culture technique, and these can be modified to suit the purpose of the experiment. So far the following procedure has been used.

Circular sheets of Eucalypt viscose pulp, $1 \mathrm{~mm}$. thick and $10 \mathrm{in}$. in diameter were marked with pencil in fifty 1 in. squares and soaked in liquid medium (see below). The moistened paper was supported at four points in a $10 \mathrm{in}$. Petri dish containing $5 \mathrm{ml} .20 \%(\mathrm{v} / \mathrm{v})$ glycerol in water to prevent drying of the paper during incubation. The dish and its contents were autoclaved at $116^{\circ}$ (10 lb./sq.in. pressure) for $15 \mathrm{~min}$. The medium contained (g./l.): cane molasses $\left(56 \%\right.$, w/v, sucrose), $40 ; \mathrm{KH}_{2} \mathrm{PO}_{4}, \mathrm{I} \cdot 0 ; \mathrm{MgSO}_{4} .7 \mathrm{H}_{2} \mathrm{O}, 0 \cdot 25 ; \mathrm{NH}_{4} \mathrm{NO}_{3}, 2 \cdot 5$. To every $100 \mathrm{ml}$. of this medium (adjusted to $\mathrm{pH} \mathrm{5.0)} 10 \mathrm{ml}$. of bromcresol green 
$(0 \cdot 4 \%, \mathrm{w} / \mathrm{v}$, in ethanol) were added. With the molasses concentration used, the colour change from green to yellow could be clearly seen.

The sterile paper was inoculated by lightly touching it with a fine dropping pipette containing the appropriately diluted spore suspension. The pipette was calibrated to deliver approximately $4000 \mathrm{vol} . / \mathrm{ml}$., each volume being that amount of fluid sufficient to cause a transient blanching of a $1 \mathrm{~mm}$. area of the indicator medium. After a little practice in timing the length of contact between the pipette and paper these volumes could be accurately delivered.

\section{Dilution of spore suspension}

In order to select mutants according to the size of the acid zones they produced on the paper culture it was important to know that the colonies arose from single spores. Confirmation of single spore implantation on the paper by direct microscopy was impossible, so an indirect method had to be devised. This was done by checking the viable counts on agar and paper culture against the direct spore count in the haemocytometer on three spore suspensions. The results (Table 1) indicate that the viable count by paper culture closely paralleled the beer wort agar plate count and both were in fair agreement with the haemocytometer count. Thus, by diluting the spore suspension according to its microscopic count, a fairly reliable means of ensuring single spore inoculation was obtained.

Table 1. Comparison of viable counts of Aspergillus niger spores with direct microscopic count

\begin{tabular}{cccc} 
& \multicolumn{3}{c}{ No. of spores $/ \mathrm{ml} \times 10^{4}$} \\
Sample & $\begin{array}{c}\text { Haemo- } \\
\text { cytometer }\end{array}$ & Agar plate & Paper culture \\
A & 200 & 140 & 140 \\
B & 100 & 70 & 90 \\
C & 50 & 30 & 60
\end{tabular}

Two further checks were introduced. Fisher (1950) showed that the distribution of cells (spores in the present instance) among a number of samples follows the Poisson formula

$$
P_{x}=\frac{m^{x}}{x} \mathrm{e}^{-m}
$$

where $\boldsymbol{P}_{\boldsymbol{x}}$ is the proportion of samples containing $x$ spores, when the average number of spores/unit volume is $m$. As the colonies which develop from more than one spore are irregular in size and shape, it is possible to apply this formula to spores cultivated on paper. Close agreement between calculated and observed findings was reached, as shown in Table 2. For instance, when the average number of spores/unit volume (i.e. per drop) was adjusted by haemocytometer count to $\mathbf{0} \cdot \mathbf{3}, \mathbf{8 5} \%$ of the colonies had regular size and shape and hence arose from single spores. The calculated figure was $86 \%$.

Thus, the irradiated spore suspension was diluted to contain 1500 viable spores/ml. (calculated from the killing curve) for a pipette calibrated to deliver 
4000 drops/ml., i.e. $0 \cdot 3$ spores/drop. The paper was inoculated by lightly touching the centre of each marked square with the pipette, incubated at $28^{\circ}$, and examined each day for 6 days.

Table 2. Comparison between numbers of calculated and observed colonies arising from single spores on paper culture

\begin{tabular}{|c|c|c|c|c|}
\hline \multirow{2}{*}{$\begin{array}{l}\text { No. of spores/ } \\
\text { unit vol. }\end{array}$} & \multicolumn{2}{|c|}{$\begin{array}{l}\text { Percentage inoculations of unit } \\
\text { volumes showing colonies }\end{array}$} & \multicolumn{2}{|c|}{$\begin{array}{l}\text { Percentage of colonies arising } \\
\text { from single spores }\end{array}$} \\
\hline & Calculated & Observed & Calculated & Observed \\
\hline $0 \cdot 3$ & 26 & $\begin{array}{l}\text { Av. } 28 \\
(31,25,30,26)\end{array}$ & 86 & $\begin{array}{l}\text { Av. } 85 \\
(84,85,87,8.5)\end{array}$ \\
\hline
\end{tabular}

Plate 1, fig. 1, shows the paper culture dish and Pl. 1, fig. 2, the colonies of selected mutants after 4 days of incubation at $28^{\circ}$. The colonies which developed on the paper were like those on agar with respect to colour, sporulation and aerial growth. The acid-yielding capacity of different colonies was determined by dividing the diameter of the acid zone by the diameter of the colony, and the figure so obtained was called the 'acid unitage'. In this way it was possible to compare, in a semi-quantitative way, acid production by strains with widely differing growth rates (see Table 3). The acid unitage was estimated for each colony and colonies which gave higher values than the parent strain were transferred to beer wort agar slopes for subsequent tests of purity and for screening of fermentation ability.

\section{Screening of mutants}

Preliminary fermentation tests with selected strains were carried out by the surface culture method, with cane molasses as the substrate. The medium contained (g./l. tap water): cane molasses, 280 (equivalent to $157 \mathrm{~g}$. sucrose); $\mathrm{KH}_{2} \mathrm{PO}_{4}, 1 \cdot 0 ; \mathrm{MgSO}_{4} \cdot 7 \mathrm{H}_{2} \mathrm{O}, 0 \cdot 25 ; \mathrm{NH}_{4} \mathrm{NO}_{3}, 2 \cdot 5$; adjusted to $\mathrm{pH} 5 \cdot 0$. This medium was dispensed in $100 \mathrm{ml}$. amounts in $500 \mathrm{ml}$. conical flasks and autoclaved at $116^{\circ}$ (10 lb./sq.in. pressure) for $15 \mathrm{~min}$. The inoculum consisted of $3 \times 10^{6}$ spores harvested from beer wort agar slopes and suspended in water containing Soaxit (sodium dioctyl sulphosuccinate, 1/10,000); incubation was at $28^{\circ}$ for 5-9 days. Cultures were analysed after different periods since information on rate, as well as degree, of citric acid yields was desired.

\section{RESULTS}

Table 3 shows the yields of citric acid obtained by surface fermentation of cane molasses, and brings out the interesting correlation between the fermentative activity of the various strains and their acid unitage. The mutant strains gave uniformly higher yields of citric acid (confirmed by chromatographic analysis) than the parent strain; the increase was approximately sixfold with the most active fermenters (cf. 72-4 and V 7-1). Further, it will be noted that successive mutations (see Gardner et al. 1956) resulted in progressively increasing yields 
as, for instance, in the series $\mathrm{X} 20, \mathrm{~V} 7, \mathrm{~V} 7-\mathbf{1}$ and $\mathrm{V} 7-2$. These consistently high yields (greater than $30 \%$ for five out of the seven mutants) were most encouraging in view of the high metal content of cane molasses. In this connexion it might be noted that the calculated manganese content of our medium was about $6 \mathrm{mg}$./l.- -6000 times greater than the optimal concentration found by Shu \& Johnson (1947) for strain 72-4. Further, the stability of strains X 20 and $V 7-1$ was evident in that they showed no decrease in acid production after fifteen successive subcultures during a period of 4 months on beer wort agar.

Table 3. Correlation of 'acid unitage' with yields of citric acid in surface fermentation of cane molasses

$\begin{array}{lcccc}\text { Strain } & \begin{array}{c}\text { Colony } \\ \text { diameter } \\ (\text { mm. })\end{array} & \begin{array}{c}\text { Acid zone } \\ \text { diameter } \\ (\text { mm. })\end{array} & \begin{array}{c}\text { Acid } \\ \text { unitage }\end{array} & \begin{array}{c}\text { Yield of } \\ \text { eitric acid * } \\ (\%)\end{array} \\ 72-4 & 15 & 25 & 1 \cdot 7 & 5 \\ \text { X } 20 & 6 & 14 & 2 \cdot 3 & 14 \\ \text { V 4 } & 4 & 10 & 2 \cdot 5 & 20 \\ \text { V 4-1 } & 2 & 11 & 5 \cdot 5 & 32 \\ \text { V 4-2 } & 3 & 17 & 5 \cdot 7 & 32 \\ \text { V7 } & 4 & 21 & 5 \cdot 2 & 30 \\ \text { V } 7-1 & 4 & 22 & 5 \cdot 5 & 32 \\ \text { V 7-2 } & 3 & 20 & 6 \cdot 6 & 35 \\ & * \text { Calculated on total sugar available. } & \end{array}$

The second point worth mentioning is that our new method of paper culture has proved eminently suitable for isolating and selecting high acid-yielding mutants. That direct selection of mutants on their acid unitage value is reliable has been confirmed by surface (Table 3) and submerged fermentations (Gardner et al. 1956). A good citric acid-producing strain should have an acid unitage of 5 or more.

\section{DISCUSSION}

The main object of this paper has been to draw attention to the technique of cultivating mould spores on absorbent paper previously soaked in an indicator medium, as a method of isolating and characterizing biochemically interesting mutants. A specific application of this method is described here for selecting high yielding citric acid-producing mutants of Aspergillus niger.

Several advantages over the usual agar-containing media may be claimed for paper culture. For example, colonies of Aspergillus niger grow compactly on paper culture with diameters less than $2 \mathrm{~cm}$. after 4 days, and the diffusion of acid metabolic products is similarly restricted. Thus it is possible to cultivate on the same surface area many more colonies than would be accommodated on the agar media. In this way paper culture greatly facilitates the isolation and characterization of mould colonies with economy of space, media and equipment. Further, in the present instance it was possible to estimate the potentiality of isolates directly by a ratio termed the acid unitage, obtained by dividing the diameter of the acid zone by that of the colony. A strain having 


\section{Journal of General Microbiology, Vol. 14, No. 2}

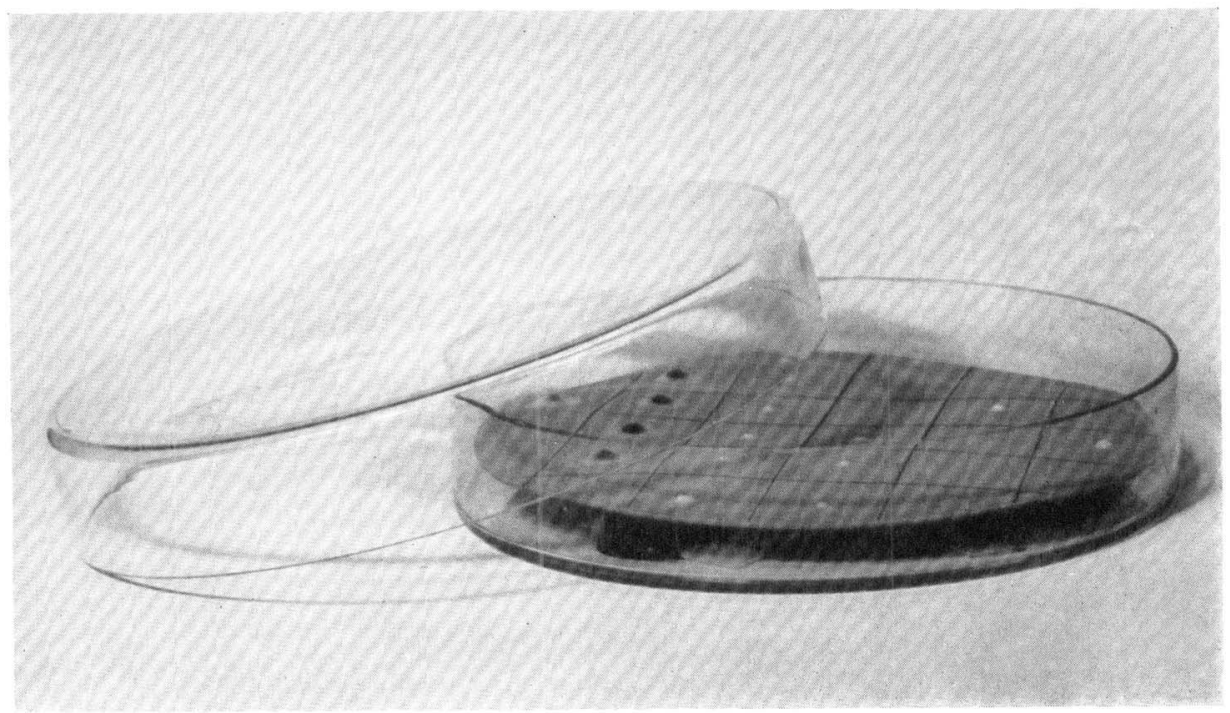

Fig. 1

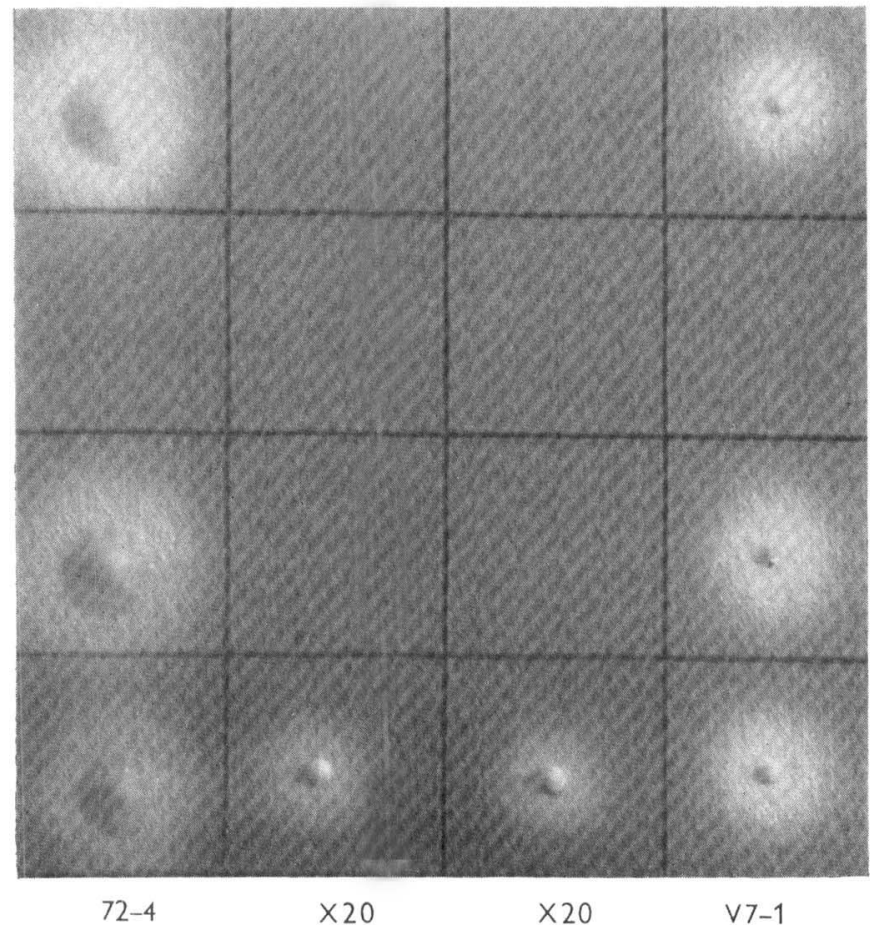

Fig. 2

L. V. James, S. D. Rubbo \& J. F. Garuner-Isolation of MUtants by paper culturk. Plat'e 1 
an acid unitage greater than 5 could be classed as a high citric acid-producer and worthy of further study. While our interest has been directed towards selecting mutants producing high yields of citric acid the method could be easily modified for other purposes, e.g. large-scale testing of antifungal agents or the selection of auxotrophic mutants of fungi.

\section{REFERENCES}

Fisher, R. A. (1950). Statistical Methods for Research Workers, 11th ed., revised. London: Oliver and Boyd.

Foster, J. W. \& Davis, H. (1949). Detection and occurrence of acid-producing fungi. Bull. Torrey bot. Cl. 76, 174.

Gardner, J. F., James, L. V. \& Rubbo, S. D. (1956). Production of citric acid by mutants of Aspergillus niger. J. gen. Microbiol. 14, 228.

Quilico, A., Panizzi, L. \& Visconti, N. (1949). Richerche sulla fermentazione citrica con mutanti di Aspergillus niger. R.C. Accad. Lincei, 6, 40.

Shu, P. \& Johnson, M. J. (1947). Effect of the composition of the sporulation medium on citric acid production of Aspergillus niger in submerged culture. J. Bact. 54, 161.

\section{EXPLANATION OF PLATE}

Fig. 1. Ten-inch Petri dish containing sporulating parent strain and non-sporulating mutants on paper culture after 6 days of incubation at $28^{\circ}$.

Fig. 2. Colonies of Aspergillus niger strains 72-4, X20 and V7-1 on paper culture, showing acid zones after 4 days of incubation at $28^{\circ}$. Note the varying size of the colonies and acid zones. For calculation of degree of acid production, 'acid unitage', see Table 3. 